\title{
NON-SINGULAR METHOD OF FUNDAMENTAL SOLUTIONS FOR THREE-DIMENSIONAL ISOTROPIC ELASTICITY PROBLEMS WITH DISPLACEMENT BOUNDARY CONDITIONS
}

\author{
NESINGULARNA METODA FUNDAMENTALNIH REŠITEV ZA \\ DEFORMACIJO TRIDIMENZIJSKIH ELASTIČNIH PROBLEMOV Z \\ DEFORMACIJSKIMI ROBNIMI POGOJI
}

\author{
Qingguo Liu ${ }^{1}$, Božidar Šarler ${ }^{1,2}$ \\ ${ }^{1}$ University of Nova Gorica, Vipavska 13, 5000 Nova Gorica, Slovenia \\ 2Institute of Metals and Technology, Lepi pot 11, 1000 Ljubljana, Slovenia \\ Qingguo.Liu@ung.si, bozidar.sarler@imt.si \\ Prejem rokopisa - received: 2015-04-23; sprejem za objavo - accepted for publication: 2015-10-09
}

doi:10.17222/mit.2015.086

\begin{abstract}
The purpose of the present paper is to develop the Non-Singular Method of Fundamental Solutions (NMFS) based on the boundary-distributed source method for three-dimensional elasticity problems with displacement boundary conditions. In the NMFS, the source points and the collocation points coincide and both are positioned on the boundary of the problem domain. In this case, the fundamental solution is singular. In order to remove the singularities of the fundamental solution, the concentrated point sources are replaced by the distributed sources over the sphere around the singularity. The values of the distributed sources are calculated directly in the case of displacement boundary conditions for isotropic problems. The performance of the novel approach is shown on two three-dimensional elastic problems with displacement boundary conditions. The method requires the discretization of the boundary only and shows excellent accuracy. It represents an efficient alternative to the classic numerical methods. The developments lead to the possibility of modelling micromechanical problems without the discretization of the interor of each of the grains, like required in classic numerical methods.

Keywords: linear isotropic elasticity, non-singular method of fundamental solutions, boundary meshless method

Namen članka je razvoj nesingularne metode fundamentalnih rešitev (NMFS) na podlagi robno distribuirane metode izvirov za tridimenzijske probleme linearne elastičnosti z deformacijskimi robnimi pogoji. V NMFS se izvirne in kolokacijske točke skladajo in so pozicionirane na robu obravnavanega območja. V tem primeru je fundamentalna rešitev singularna. Za odstranitev singularnosti fundamentalne rešitve so koncentrirani izviri nadomeščeni s porazdeljenimi izviri po krogli okoli singularnosti Vrednosti porazdeljenih izvirov so neposredno izračunane pri Dirichletovih robnih pogojih za izotropne probleme. Značilnosti novega načina so prikazane na dveh primerih tridimenzijskih problemov z deformacijskimi robnimi pogoji. Metoda zahteva zgolj diskretizacijo roba in prikazuje odlično natančnost. Pomeni tudi učinkovito alternativo klasičnim numeričnim metodam. Opisani razvoj vodi do možnosti simulacije mikromehanskih problemov brez diskretizacije notranjosti zrn, kot je to potrebno pri klasičnih numeričnih metodah.

Ključne besede: linerna izotropna elastičnost, nesingularna metoda fundamentalnih rešitev, robna brezmrežna metoda
\end{abstract}

\section{INTRODUCTION}

The main idea of MFS ${ }^{1}$ consists of approximating the solution of the partial differential equation by a linear combination of fundamental solutions, defined in source points. The expansion coefficients are calculated by collocation or a least-squares fit of the boundary conditions. The fundamental solution is usually singular in the source points and this is the reason why the source points are located outside the domain in the MFS. In this case, the original problem is reduced to determining the unknown coefficients of the fundamental solutions and the coordinates of the source points by requiring the approximation to satisfy the boundary conditions and hence solving a non-linear problem. If the source points are a priori fixed, then the coefficients of the MFS approximation are determined by solving a linear problem. The MFS has become very popular in recent years because of its simplicity ${ }^{2-5}$ and for 3D problems. ${ }^{6,7}$
In the traditional MFS, a fictitious boundary, positioned outside the problem domain, is required to place the source points. This is very impractical or even impossible, particularly when solving muti-body problems. In recent years, various efforts have been made, with the aim being to remove this barrier in the MFS, so that the source points can be placed on the real boundary directly $^{8-12}$ In the present paper, we use a Non-Singular MFS based on ${ }^{8}$ to deal with the three-dimensional isotropic elasticity problems with displacement boundary condition. The application of a non-singular method of fundamental solutions (NMFS) in two-dimensional isotropic and anisotropic linear elasticity has been originally developed. ${ }^{13-15}$ We respectively used area-distributed sources covering the source points to replace the concentrated point sources. This NMFS approach also does not require any information about the neighboring points for each source point, thus it is a truly a meshfree 
boundary method. The present develoments are dedicated to enabling NMFS for solving three-dimensional micromechanical elasticity problems. This is of utmost importance in the simulation of an effective Young's modulus and Poisson's ratio for multigrain systems that appear in many engineering systems.

The rest of the paper is structured as follows. The governing equations are shown in matrix form. The solution procedure is given for MFS and NMFS. A three-dimensional example in two cases, translation and deformation, is given, followed by the conclusions and future research.

\section{GOVERNING EQUATIONS}

Consider a 3D domain $\Omega$ with the boundary $\Gamma$ filled with isotropic elasticity materials. Let us introduce a 3D Cartesian coordinate system with the orthonormal base vectors $\mathbf{i}_{x}, \mathbf{i}_{y}$ and $\mathbf{i}_{z}$ and the coordinates $p_{x}, p_{y}$ and $p_{z}$ of the position vector $\mathbf{p}$, i.e., $\mathbf{p}=p_{x} \mathbf{i}_{x}+p_{y} \mathbf{i}_{y}+p_{z} \mathbf{i}_{z}$. To simplify the calculations we shall assume that (i) the solid is free of body forces and (ii) the thermal strains can be neglected. Under these conditions the general equation of elasticity ${ }^{16}$ is:

$$
C_{\zeta \xi v \tau} \frac{\partial^{2} u_{v}(\mathbf{p})}{\partial p_{\xi} \partial p_{\tau}}=0, \quad \zeta, \xi, v, \tau=x, y, z
$$

where $u_{v}$ are the displacements, $C_{\zeta \xi v \tau}$ are the elastic stiffnesses and the components of a fourth rank stiffness tensor: ${ }^{17}$

$$
\left.\mathbf{C}=C_{\xi \xi v z} \mid \begin{array}{llllll}
C_{x x x x} & C_{x x y y} & C_{x x z z} & C_{x x y z} & C_{x x x z} & C_{x x y y} \\
C_{x x y y} & C_{y y y y} & C_{y y z z} & C_{y y y z} & C_{x z y y} & C_{x y y y} \\
C_{x x z z} & C_{y y z z} & C_{z z z z} & C_{y z z z} & C_{x z z z} & C_{x y z z} \\
C_{x x y z} & C_{y y y z} & C_{y z z z} & C_{y z y z} & C_{x z y z} & C_{x y y z} \\
C_{x x x z} & C_{x z y y} & C_{x z z z} & C_{x z y z} & C_{x z x z} & C_{x y x z} \\
C_{x x x y} & C_{x y y y} & C_{x y z z} & C_{x y y z} & C_{x y x z} & C_{x y x y}
\end{array}\right]=
$$$$
=\left[\begin{array}{llllll}
c_{11} & c_{12} & c_{13} & c_{14} & c_{15} & c_{16} \\
c_{12} & c_{22} & c_{23} & c_{24} & c_{25} & c_{26} \\
c_{13} & c_{23} & c_{33} & c_{34} & c_{35} & c_{36} \\
c_{14} & c_{24} & c_{34} & c_{44} & c_{45} & c_{46} \\
c_{15} & c_{25} & c_{35} & c_{45} & c_{55} & c_{56} \\
c_{16} & c_{26} & c_{36} & c_{46} & c_{56} & c_{66}
\end{array}\right]
$$

In subsequent discussions, it will be convenient to write the equilibrium Equation (1) in matrix form as:

$$
\begin{aligned}
& {\left[\begin{array}{cccccc}
\frac{\partial}{\partial p_{x}} & 0 & 0 & \frac{\partial}{\partial p_{y}} & \frac{\partial}{\partial p_{z}} & 0 \\
0 & \frac{\partial}{\partial p_{y}} & 0 & \frac{\partial}{\partial p_{x}} & 0 & \frac{\partial}{\partial p_{z}} \\
0 & 0 & \frac{\partial}{\partial p_{z}} & 0 & \frac{\partial}{\partial p_{x}} & \frac{\partial}{\partial p_{y}}
\end{array}\right]} \\
& {\left[\begin{array}{cccccc}
c_{11} & c_{12} & c_{13} & c_{14} & c_{15} & c_{16} \\
c_{12} & c_{22} & c_{23} & c_{24} & c_{25} & c_{26} \\
c_{13} & c_{23} & c_{33} & c_{34} & c_{35} & c_{36} \\
c_{14} & c_{24} & c_{34} & c_{44} & c_{45} & c_{46} \\
c_{15} & c_{25} & c_{35} & c_{45} & c_{55} & c_{56} \\
c_{16} & c_{26} & c_{36} & c_{46} & c_{56} & c_{66}
\end{array}\right] \cdot\left[\begin{array}{c}
\partial u_{x} \partial p_{x} \\
\partial u_{y} \partial p_{y} \\
\partial u_{z} \partial p_{z} \\
\partial u_{y} \partial p_{z}+\partial u_{z} \partial p_{y} \\
\partial u_{x} \partial p_{z}+\partial u_{z} \partial p_{x} \\
\partial u_{x} \partial p_{y}+\partial u_{y} \partial p_{x}
\end{array}\right]=0}
\end{aligned}
$$

The stresses $\sigma_{\xi \xi}$ are related to the strains through the generalized Hooke's law:

$$
\boldsymbol{\sigma}=\mathbf{C} \varepsilon
$$

where $C_{\zeta \xi v \tau}$ satisfy the fully symmetrical conditions:

$$
C_{\zeta \xi v \tau}=C_{\xi \xi v \tau}, C_{\zeta \xi v \tau}=C_{\zeta \xi \tau v}, C_{\zeta \xi v \tau}=C_{v \tau \xi \xi}
$$

$\boldsymbol{\varepsilon}$ is the strains vector:

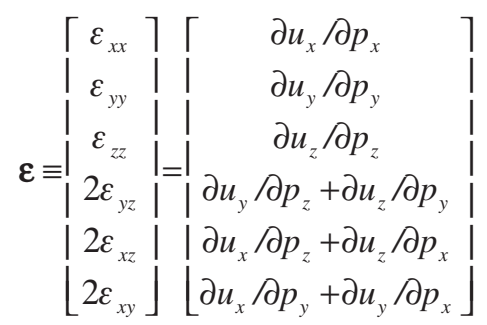

\section{SOLUTION PROCEDURE}

The fundamental solution for the isotropic elasticity is given ${ }^{18}$ in three dimensions (3D) by:

$$
\begin{aligned}
& U_{\zeta \xi}(\mathbf{p}, \mathbf{s})=\frac{1}{16 \pi \mu(1-v) r} . \\
& \left\{(3-4 v) \delta_{\zeta \xi}+\frac{\left(p_{\zeta}-s_{\zeta}\right)\left(p_{\xi}-s_{\xi}\right)}{r^{2}}\right\}, \zeta, \xi=x, y, z
\end{aligned}
$$

where $U_{\zeta \xi}(\mathbf{p}, \mathbf{s})$ represents the displacement in the direction $\zeta$ at point $\mathbf{p}$ due to a unit point force acting in the direction $\xi$ at point $\mathbf{s} . r=\left[\left(p_{x}-s_{x}\right)^{2}+\left(p_{y}-s_{y}\right)^{2}+\left(p_{z}-s_{z}\right)^{2}\right]^{1 / 2}$ is the distance between the point $\mathbf{p}$ and the source point s. Equation (7) is expanded as follows: 


$$
\begin{aligned}
& U_{x x}=\frac{1}{16 \pi \mu(1-v) r}\left[(3-4 v)+\frac{\left(p_{x}-s_{x}\right)^{2}}{r^{2}}\right] \\
& U_{y y}=\frac{1}{16 \pi \mu(1-v) r}\left[(3-4 v)+\frac{\left(p_{y}-s_{y}\right)^{2}}{r^{2}}\right] \\
& U_{z z}=\frac{1}{16 \pi \mu(1-v) r}\left[(3-4 v)+\frac{\left(p_{z}-s_{z}\right)^{2}}{r^{2}}\right] \\
& U_{x y}=U_{y x}=\frac{1}{16 \pi \mu(1-v) r} \frac{\left(p_{x}-s_{x}\right)\left(p_{y}-s_{y}\right)}{r^{2}} \\
& U_{x z}=U_{z x}=\frac{1}{16 \pi \mu(1-v) r} \frac{\left(p_{x}-s_{x}\right)\left(p_{z}-s_{z}\right)}{r^{2}} \\
& U_{y z}=U_{z y}=\frac{1}{16 \pi \mu(1-v) r} \frac{\left(p_{y}-s_{y}\right)\left(p_{z}-s_{z}\right)}{r^{2}}
\end{aligned}
$$

It can be shown that the following $u_{x}, u_{y}$ and $u_{z}$ satisfy the governing Equations (3):

$$
\begin{aligned}
& u_{x}(\mathbf{p})=U_{x x}(\mathbf{p}, \mathbf{s}) \alpha+U_{x y}(\mathbf{p}, \mathbf{s}) \beta+U_{x z}(\mathbf{p}, \mathbf{s}) \gamma \\
& u_{y}(\mathbf{p})=U_{y x}(\mathbf{p}, \mathbf{s}) \alpha+U_{y y}(\mathbf{p}, \mathbf{s}) \beta+U_{y z}(\mathbf{p}, \mathbf{s}) \gamma \\
& u_{z}(\mathbf{p})=U_{z x}(\mathbf{p}, \mathbf{s}) \alpha+U_{z y}(\mathbf{p}, \mathbf{s}) \beta+U_{z z}(\mathbf{p}, \mathbf{s}) \gamma
\end{aligned}
$$

where $\alpha, \beta$ and $\gamma$ represent arbitrary constants. The fundamental solution $U_{\zeta \xi}(\mathbf{p}, \mathbf{s})$ is singular when $\mathbf{p}=\mathbf{s}$. We use the desingularization technique, proposed by $\mathrm{Liu}^{8}$ for evaluating the singular values. We modify his approach in a sense of preserving the original fundamental solution at all the points except the singularity, and by scaling the singularity with the area of the sphere over which the desingularization integration is performed. This allows us to treat the MFS and the NMFS in formally the same way. The desingularization (transformation of $U_{\xi \xi}(\mathbf{p}, \mathbf{s})$ into $\left.\widetilde{U}_{\xi \xi}(\mathbf{p}, \mathbf{s})\right)$ is thus performed in the following way:

$$
\tilde{U}_{\zeta \xi}(\mathbf{p}, \mathbf{s})=\left\{\begin{array}{cc}
U_{\zeta \xi}(\mathbf{p}, \mathbf{s}) & r>R \\
\frac{1}{\pi R^{2}} \int_{A(\mathbf{s}, R)} U_{\zeta \xi}(\mathbf{p}, \mathbf{s}) \mathrm{d} A & r \leq R
\end{array}\right.
$$

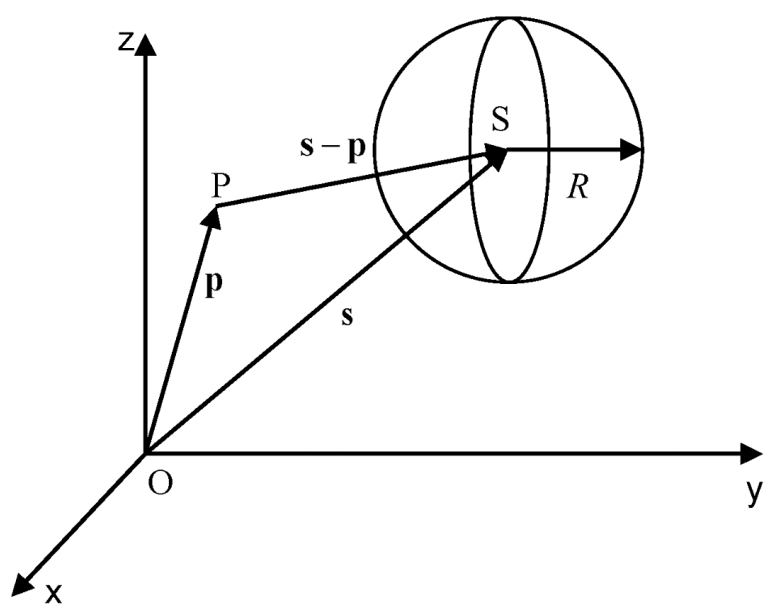

Figure 1: Distributed source on a sphere $A(\mathbf{s}, R)$ with radius $R$ Slika 1: Porazdeljeni izviri na krogli $A(\mathbf{s}, R) \mathrm{z}$ radijem $R$ where $A(\mathbf{s}, R)$ represents a sphere with radius $R$, centered around $\mathbf{s}$. The involved integrals can be calculated as follows (by using the integration in polar coordinates $p_{x}-s_{x}=r \sin \varphi \cos \theta, p_{y}-s_{y}=r \sin \varphi \sin \theta$ and $p_{z}-s_{z}=$ $r \cos \varphi$, Figure 1):

$$
\begin{aligned}
& \widetilde{U}_{x x}(\mathbf{p}, \mathbf{p})=\widetilde{U}_{y y}(\mathbf{p}, \mathbf{p})=\widetilde{U}_{z z}(\mathbf{p}, \mathbf{p})=\frac{5-6 v}{16 \pi \mu(1-v) R} \\
& \widetilde{U}_{x y}(\mathbf{p}, \mathbf{p})=\widetilde{U}_{y x}(\mathbf{p}, \mathbf{p})=0 \\
& \widetilde{U}_{x z}(\mathbf{p}, \mathbf{p})=\widetilde{U}_{z x}(\mathbf{p}, \mathbf{p})=0 \\
& \widetilde{U}_{y z}(\mathbf{p}, \mathbf{p})=\widetilde{U}_{z y}(\mathbf{p}, \mathbf{p})=0
\end{aligned}
$$

It can also be shown that the following $u_{x}, u_{y}$ and $u_{z}$ satisfy the governing Equations (3):

$$
\begin{aligned}
& u_{x}(\mathbf{p})=\widetilde{U}_{x x}(\mathbf{p}, \mathbf{s}) \alpha+\widetilde{U}_{x y}(\mathbf{p}, \mathbf{s}) \beta+\widetilde{U}_{x z}(\mathbf{p}, \mathbf{s}) \gamma \\
& u_{y}(\mathbf{p})=\widetilde{U}_{y x}(\mathbf{p}, \mathbf{s}) \alpha+\widetilde{U}_{y y}(\mathbf{p}, \mathbf{s}) \beta+\widetilde{U}_{y z}(\mathbf{p}, \mathbf{s}) \gamma \\
& u_{z}(\mathbf{p})=\widetilde{U}_{z x}(\mathbf{p}, \mathbf{s}) \alpha+\widetilde{U}_{z y}(\mathbf{p}, \mathbf{s}) \beta+\widetilde{U}_{z z}(\mathbf{p}, \mathbf{s}) \gamma
\end{aligned}
$$

The solution of the problem is sought in the form:

$u_{x}(\mathbf{p})=\sum_{n=1}^{N} \widetilde{U}_{x x}\left(\mathbf{p}, \mathbf{p}_{n}\right) \alpha_{n}+\sum_{n=1}^{N} \widetilde{U}_{x y}\left(\mathbf{p}, \mathbf{p}_{n}\right) \beta_{n}+$ $+\sum_{n=1}^{N} \widetilde{U}_{x z}\left(\mathbf{p}, \mathbf{p}_{n}\right) \gamma_{n}$

$u_{y}(\mathbf{p})=\sum_{n=1}^{N} \widetilde{U}_{y x}\left(\mathbf{p}, \mathbf{p}_{n}\right) \alpha_{n}+\sum_{n=1}^{N} \widetilde{U}_{y y}\left(\mathbf{p}, \mathbf{p}_{n}\right) \beta_{n}+$ $+\sum_{n=1}^{N} \widetilde{U}_{y z}\left(\mathbf{p}, \mathbf{p}_{n}\right) \gamma_{n}$

$u_{z}(\mathbf{p})=\sum_{n=1}^{N} \widetilde{U}_{z x}\left(\mathbf{p}, \mathbf{p}_{n}\right) \alpha_{n}+\sum_{n=1}^{N} \widetilde{U}_{z y}\left(\mathbf{p}, \mathbf{p}_{n}\right) \beta_{n}+$ $+\sum_{n=1}^{N} \widetilde{U}_{z z}\left(\mathbf{p}, \mathbf{p}_{n}\right) \gamma_{n}$

The coefficients $\alpha_{n}, \beta_{n}$ and $\gamma_{n}$ are calculated from a system of $3 N$ algebraic equations:

$$
\mathbf{A x}=\mathbf{b}
$$

where $\mathbf{A}$ stands for a $3 N \times 3 N$ matrix with the entries $A_{i j}, \mathbf{x}$ is a $3 N \times 1$ vector with the entries $x_{i}$, and $\mathbf{b}$ is a $3 N$ $\times 1$ vector with entries $b_{i}$ :

$$
\begin{aligned}
& A_{i j}=\widetilde{U}_{x x}\left(\mathbf{p}_{i}, \mathbf{p}_{j}\right), \quad A_{i(N+j)}=\widetilde{U}_{x y}\left(\mathbf{p}_{i}, \mathbf{p}_{j}\right) \\
& A_{i(2 N+j)}=\widetilde{U}_{x z}\left(\mathbf{p}_{i}, \mathbf{p}_{j}\right), \quad A_{(N+i) j}=\widetilde{U}_{y x}\left(\mathbf{p}_{i}, \mathbf{p}_{j}\right) \\
& A_{(N+i)(N+j)}=\widetilde{U}_{y y}\left(\mathbf{p}_{i}, \mathbf{p}_{j}\right), \quad A_{(N+i)(2 N+j)}=\widetilde{U}_{y z}\left(\mathbf{p}_{i}, \mathbf{p}_{j}\right) \\
& A_{(2 N+i) j}=\widetilde{U}_{z x}\left(\mathbf{p}_{i}, \mathbf{p}_{j}\right), \quad A_{(2 N+i)(N+j)}=\widetilde{U}_{z y}\left(\mathbf{p}_{i}, \mathbf{p}_{j}\right) \\
& A_{(2 N+i)(2 N+j)}=\widetilde{U}_{z z}\left(\mathbf{p}_{i}, \mathbf{p}_{j}\right), \quad i, j=1,2, \ldots, N \\
& x_{i}=\alpha_{i}, \quad x_{(N+i)}=\beta_{i}, \quad x_{(2 N+i)}=\gamma_{i}, \quad i=1,2, \ldots, N \\
& b_{i}=u_{x}\left(\mathbf{p}_{i}\right), b_{(N+i)}=u_{y}\left(\mathbf{p}_{i}\right), b_{(2 N+i)}=u_{z}\left(\mathbf{p}_{i}\right), \\
& i=1,2, \ldots, N
\end{aligned}
$$


By knowing all the elements $A_{i j}$ and $b_{i}$ of the system (20), we can determine the values of $x_{i}$ (i.e., $\alpha_{n}, \beta_{n}$ and $\left.\gamma_{n}\right)$. Afterwards, we can calculate the solution of the governing equation from:

$u_{\zeta}(\mathbf{p})=\sum_{n=1}^{N} \widetilde{U}_{\zeta x}\left(\mathbf{p}, \mathbf{p}_{n}\right) \alpha_{n}+\sum_{n=1}^{N} \widetilde{U}_{\zeta y}\left(\mathbf{p}, \mathbf{p}_{n}\right) \beta_{n}+$

$+\sum_{n=1}^{N} \widetilde{U}_{\xi z}\left(\mathbf{p}, \mathbf{p}_{n}\right) \gamma_{n}, \quad \xi=x, y, z$

where $\mathbf{p}$ is any point inside the domain or on the boundary.

\section{NUMERICAL EXAMPLES}

We consider a cube with the side length $a=2 \mathrm{~m}$ centered around $p_{x}=0 \mathrm{~m}, p_{y}=0 \mathrm{~m}, p_{z}=0 \mathrm{~m}$. The elastic media is defined by $E=1 \mathrm{~N} / \mathrm{m}^{2}, v=0.3$.

\subsection{Translation}

We consider a solution of the governing equations in this cube subject to the boundary conditions $\bar{u}_{x}=2 \mathrm{~m}, \bar{u}_{y}$ $=2 \mathrm{~m}, \bar{u}_{z}=2 \mathrm{~m}$. The analytical solution is:

$$
u_{x}=2 \mathrm{~m}, u_{y}=2 \mathrm{~m}, u_{z}=2 \mathrm{~m},
$$

A plot of the translation, obtained with the analytical solution and the numerical solutions with MFS and NMFS, is shown in Figure 2 for the case with 150 nodes ( 25 nodes on each side of he cube). The distance of the fictitious boundary from the true boundary for the MFS is set $R_{M}=5 d$, where $d$ is the smallest distance between two nodes on the boundary. The radius of the sphere for the distributed area source covering each node is set to $R$ $=d / 3$.

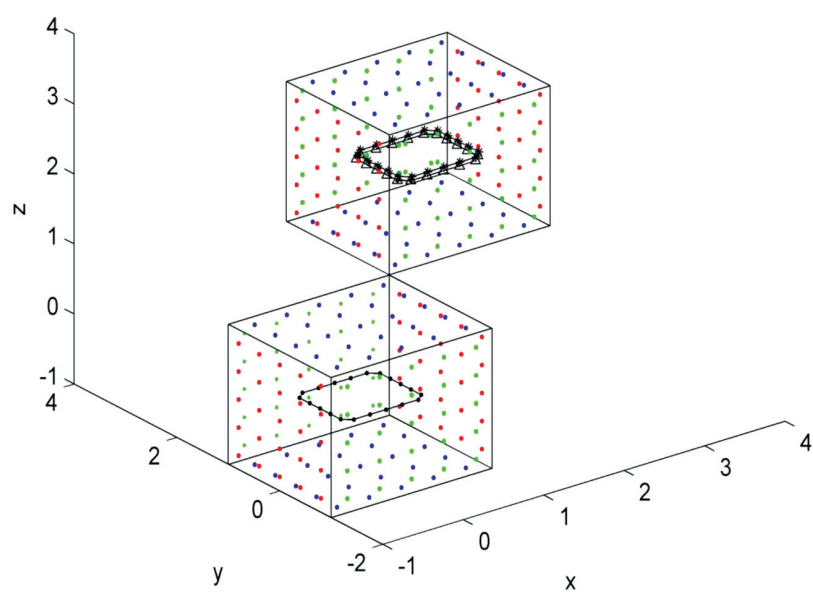

Figure 2: The analytical solution and the numerical solution of MFS and NMFS for the translation case with $N=150, R=d / 3, R_{M}=5 d$ $(\bullet$ : collocation points, + : analytical solution, $\mathrm{x}$ : MFS solution, $\Delta$ : NMFS solution)

Slika 2: Analitična in numerična rešitev z MFS in NMFS za translacijski primer z $N=150, R=d / 3, R_{M}=5 d(\bullet:$ kolokacijske točke, + : analitična rešitev, $\mathrm{x}$ : MFS rešitev, $\Delta$ : NMFS rešitev)

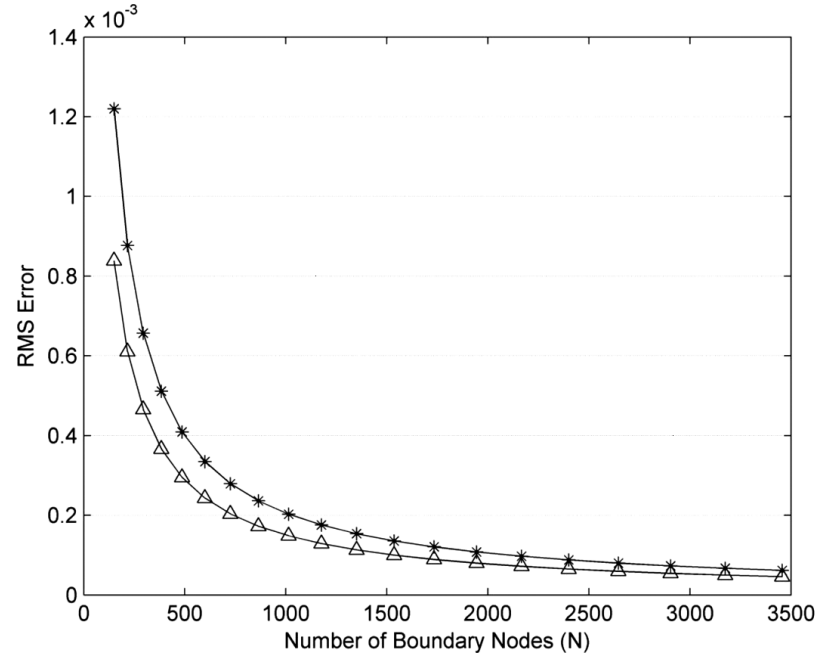

Figure 3: The relationship between the RMS errors and the number of boundary nodes for translation case, calculated by NMFS. $R=d / 3(+$ : $\left.e_{x}, \mathrm{x}: e_{y}, \Delta: e_{z}\right)$.

Slika 3: Odvisnost med RMS-napakami in številom robnih točk za translacijski primer, izračunan z NMFS. $R=d / 3\left(+: e_{x}, \mathrm{x}: e_{y}, \Delta: e_{z}\right)$.

The solution of the points on a square with the side length $a=1 \mathrm{~m}$ centered around $p_{x}=0 \mathrm{~m}, p_{y}=0 \mathrm{~m}, p_{z}=0$ $\mathrm{m}$ on the plane $p_{z}=0$ are computed and compared with the analytical solutions. The root-mean-square (RMS) errors of the numerical solution are defined as:

$$
e_{\zeta}=\sqrt{\frac{1}{N} \sum_{n=1}^{N}\left(\underline{u}_{\zeta n}-u_{\zeta n}\right)^{2}}, \quad \zeta=x, y
$$

Table 1: RMS errors of NMFS solutions for the translation case with $R=d / 3$

Tabela 1: RMS-napake NMFS-rešitev za translacijski primer z $R=$

\begin{tabular}{|c|c|c|c|}
\hline $\begin{array}{l}\text { Num. of boun- } \\
\text { dary nodes }(N)\end{array}$ & $e_{x}\left(\times 10^{-3}\right)$ & $e_{y}\left(\times 10^{-3}\right)$ & $e_{z}\left(\times 10^{-3}\right)$ \\
\hline 150 & 1.2200 & 1.2200 & 0.8390 \\
\hline 216 & 0.8769 & 0.8769 & 0.6109 \\
\hline 294 & 0.6570 & 0.6570 & 0.4658 \\
\hline 384 & 0.5112 & 0.5112 & 0.365 \\
\hline 486 & 0.4091 & 0.4091 & 0.2950 \\
\hline 600 & 0.3348 & 0.3348 & 0.2428 \\
\hline 726 & 0.2791 & 0.2791 & 0.2033 \\
\hline 864 & 0.2363 & 0.2363 & 0.1727 \\
\hline 1014 & 0.2026 & 0.2026 & 0.1485 \\
\hline 1176 & 0.1757 & 0.1757 & 0.1291 \\
\hline 1350 & 0.1538 & 0.1538 & 0.1132 \\
\hline 1536 & 0.1357 & 0.1357 & 0.1001 \\
\hline 1734 & 0.1207 & 0.1207 & 0.0891 \\
\hline 1944 & 0.1080 & 0.1080 & 0.0799 \\
\hline 2166 & 0.0973 & 0.0973 & 0.0720 \\
\hline 2400 & 0.0880 & 0.0880 & 0.0652 \\
\hline 2646 & 0.0800 & 0.0800 & 0.0594 \\
\hline 2904 & 0.0731 & 0.0731 & 0.0543 \\
\hline 3174 & 0.0670 & 0.0670 & 0.0498 \\
\hline 3456 & 0.0617 & 0.0617 & 0.0459 \\
\hline
\end{tabular}
$d / 3$ 
where $\underline{u}_{\xi k}$ and $u_{\zeta k}(\zeta=x, y)$ are the analytical and the numerical solutions, respectively. The number of boundary nodes used is from 150 to 3456 .

Figure 3 shows the RMS errors of the results obtained using the NMFS. The errors are already less than $10^{-3}$ with $N=216$ and the solution converges to the analytical solution with an increasing number of nodes (Table 1). The MFS result is shown in Table 2 for $R_{M}=$ $5 d$. Here it should be noted that the MFS solution error is relatively small; however, the convergence is not uniform. This fact is due to the choice of the artificial boundary position, which was for all node arrangements $R_{M}=5 d$ and thus most probably not optimally varying.

Table 2: RMS errors of MFS solutions for the translation case with $R_{M}=5 d$

Tabela 2: RMS-napake MFS-rešitev za translacijski primer z $R_{M}=5 d$

\begin{tabular}{|c|c|c|c|}
\hline $\begin{array}{l}\text { Num. of boun- } \\
\text { dary nodes }(N)\end{array}$ & $e_{x}\left(\times 10^{-14}\right)$ & $e_{y}\left(\times 10^{-14}\right)$ & $e_{z}\left(\times 10^{-14}\right)$ \\
\hline 150 & 0.2204 & 0.2204 & 0.5548 \\
\hline 216 & 1.7907 & 1.7907 & 4.8854 \\
\hline 294 & 0.0364 & 0.0364 & 0.0794 \\
\hline 384 & 0.1590 & 0.1590 & 0.1617 \\
\hline 486 & 0.0348 & 0.0348 & 0.0017 \\
\hline 600 & 0.0058 & 0.0058 & 0.0015 \\
\hline 726 & 0.1103 & 0.1102 & 0.1631 \\
\hline 864 & 0.0004 & 0.0004 & 0.0001 \\
\hline 1014 & 0.0475 & 0.0445 & 0.0478 \\
\hline 1176 & 0.0033 & 0.0050 & 0.0025 \\
\hline 1350 & 0.0005 & 0.0003 & 0.0010 \\
\hline 1536 & 0.0038 & 0.0295 & 0.0238 \\
\hline 1734 & 0.0000 & 0.0000 & 0.0000 \\
\hline 1944 & 0.0000 & 0.0000 & 0.0000 \\
\hline 2166 & 0.0004 & 0.0004 & 0.0006 \\
\hline 2400 & 0.0000 & 0.0000 & 0.0000 \\
\hline 2646 & 0.0000 & 0.0000 & 0.0000 \\
\hline 2904 & 0.0000 & 0.0000 & 0.0000 \\
\hline 3174 & 0.0000 & 0.0001 & 0.0000 \\
\hline 3456 & 0.0000 & 0.0000 & 0.0000 \\
\hline
\end{tabular}

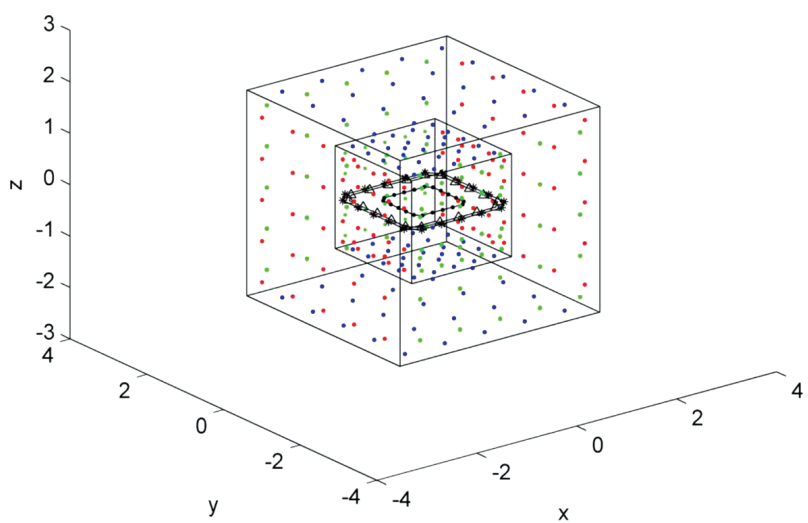

Figure 4: The analytical solution and the numerical solution of MFS and NMFS for the deformation case with $N=150, R=d / 3, R_{M}=5 d$ $(\bullet$ : collocation points, + : analytical solution, $\mathrm{x}$ : MFS solution, $\Delta$ : NMFS solution)

Slika 4: Analitična in numerična rešitev z MFS in NMFS za deformacijski primer z $N=150, R=d / 3, R_{M}=5 d(\bullet:$ kolokacijske točke, + analitična rešitev, $\mathrm{x}$ : MFS rešitev, $\Delta$ : NMFS rešitev)

\subsection{Deformation}

We consider a solution of the governing equations in this cube subject to the boundary conditions $\bar{u}_{x}=p_{x}, \bar{u}_{y}=$ $p_{y}, \bar{u}_{z}=p_{z}$. The analytical solution is:

$$
u_{x}=p_{x}, u_{y}=p_{y}, u_{z}=p_{z}
$$

A plot of the deformation, obtained with the analytical solution and the numerical solutions with MFS and NMFS, is shown in Figure 4 for the case with 150 nodes

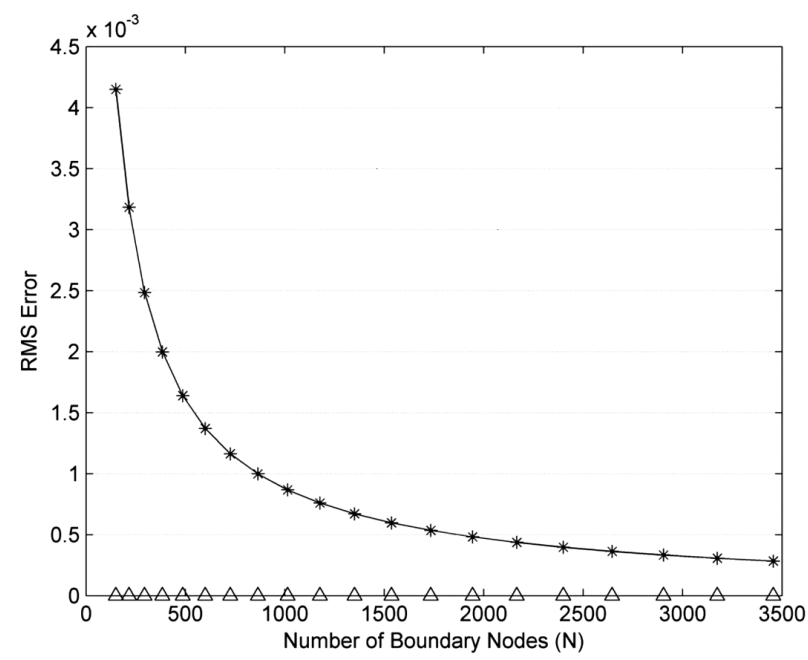

Figure 5: The relationship between the RMS errors and the number of boundary nodes for the deformation case, calculated by NMFS. $R=d / 3$ $\left(+: e_{x}, \mathrm{x}: e_{y}, \Delta: e_{z}\right)$.

Slika 5: Odvisnost med RMS-napakami in številom robnih točk za deformacijski primer, izračunan z NMFS. $R=d / 3\left(+: e_{x}, \mathrm{x}: e_{y}, \Delta: e_{z}\right)$.

Table 3: RMS errors of the NMFS solutions for the deformation case with $R=d / 3$

Tabela 3: Odvisnost med RMS-napakami in številom robnih točk za deformacijski primer, izračunan z NMFS, $R=d / 3$

\begin{tabular}{|c|c|c|c|}
\hline $\begin{array}{l}\text { Num. of boun- } \\
\text { dary nodes }(N)\end{array}$ & $e_{x}\left(\times 10^{-3}\right)$ & $e_{y}\left(\times 10^{-3}\right)$ & $e_{z}\left(\times 10^{-3}\right)$ \\
\hline 150 & 4.1487 & 4.1487 & 0.0000 \\
\hline 216 & 3.1826 & 3.1826 & 0.0000 \\
\hline 294 & 2.4837 & 2.4837 & 0.0000 \\
\hline 384 & 1.9972 & 1.9972 & 0.0000 \\
\hline 486 & 1.6395 & 1.6395 & 0.0000 \\
\hline 600 & 1.3703 & 1.3703 & 0.0000 \\
\hline 726 & 1.1623 & 1.1623 & 0.0000 \\
\hline 864 & 0.9983 & 0.9983 & 0.0000 \\
\hline 1014 & 0.8667 & 0.8667 & 0.0000 \\
\hline 1176 & 0.7596 & 0.7596 & 0.0000 \\
\hline 1350 & 0.6711 & 0.6711 & 0.0000 \\
\hline 1536 & 0.5973 & 0.5973 & 0.0000 \\
\hline 1734 & 0.5350 & 0.5350 & 0.0000 \\
\hline 1944 & 0.4820 & 0.4820 & 0.0000 \\
\hline 2166 & 0.4365 & 0.4365 & 0.0000 \\
\hline 2400 & 0.3971 & 0.3971 & 0.0000 \\
\hline 2646 & 0.3629 & 0.3629 & 0.0000 \\
\hline 2904 & 0.3329 & 0.3329 & 0.0000 \\
\hline 3174 & 0.3064 & 0.3064 & 0.0000 \\
\hline 3456 & 0.2830 & 0.2830 & 0.0000 \\
\hline & & & \\
\hline
\end{tabular}


(25 nodes on each side of the cube). The same $R$ and $R_{M}$ as with example 4.1 are used.

Figure 5 shows the RMS errors of the results obtained using the NMFS and the solution converges to the analytical solution with an increasing number of nodes (Table 3). The MFS results are shown in Table 4 for $R_{M}$ $=5 d$.

Table 4: RMS errors of the MFS solutions for the deformation case with $R_{M}=5 d$

Tabela 4: RMS-napake MFS-rešitev za deformacijski primer $R_{M}=5 d$

\begin{tabular}{|c|c|c|c|}
\hline $\begin{array}{c}\text { Num. of boun- } \\
\text { dary nodes }(N)\end{array}$ & $e_{x}\left(\times 10^{-11}\right)$ & $e_{y}\left(\times 10^{-11}\right)$ & $e_{z}\left(\times 10^{-11}\right)$ \\
\hline 150 & 0.1410 & 0.1410 & 0.0000 \\
\hline 216 & 0.0256 & 0.0256 & 0.0000 \\
\hline 294 & 0.0018 & 0.0018 & 0.0000 \\
\hline 384 & 0.0012 & 0.0012 & 0.0000 \\
\hline 486 & 0.0014 & 0.0014 & 0.0000 \\
\hline 600 & 2.1088 & 2.1088 & 0.0000 \\
\hline 726 & 0.0010 & 0.0010 & 0.0000 \\
\hline 864 & 0.0001 & 0.0001 & 0.0000 \\
\hline 1014 & 0.0000 & 0.0000 & 0.0000 \\
\hline 1176 & 0.0000 & 0.0000 & 0.0000 \\
\hline 1350 & 0.0010 & 0.0008 & 0.0019 \\
\hline 1536 & 0.0000 & 0.0002 & 0.0001 \\
\hline 1734 & 0.0000 & 0.0000 & 0.0000 \\
\hline 1944 & 0.0002 & 0.0001 & 0.0001 \\
\hline 2166 & 0.0005 & 0.0005 & 0.0008 \\
\hline 2400 & 0.0000 & 0.0000 & 0.0000 \\
\hline 2646 & 0.0000 & 0.0000 & 0.0000 \\
\hline 2904 & 0.0000 & 0.0000 & 0.0000 \\
\hline 3174 & 0.0000 & 0.0000 & 0.0000 \\
\hline 3456 & 0.0000 & 0.0000 & 0.0000 \\
\hline
\end{tabular}

\section{CONCLUSION}

A new, non-singular method of fundamental solutions ${ }^{13}$ is extended in the present paper to solve 3D linear elasticity problems. In this approach, the singular values of the fundamental solution are integrated over a small sphere, so that the coefficients in the system of equations can be evaluated analytically and consistently, leading to an extremely simple computer implementation of this method. The method essentially gives similar results as the classic MFS. It has the advantage that the artificial boundary is not present; however, the problems with the traction boundary condition have not yet been solved. The main advantage of the method is that the discretisation is performed only on the boundary of the domain and no polygonisation is needed, like in the finite-element method. The NMFS, presented in this paper, can be adapted or extended to handle many related problems, such as anisotropic elasticity, and multi-body problems, which all represent directions for our further investigations. The advantage of not having to generate the artificial boundary is particularly welcome in these types of problems. The method will be used in the future for the calculation of $3 \mathrm{D}$ enginering deformation problems in steel and aluminium alloys, with realistic grain shapes, obtained from microscope images. The developed method is believed to represent the simplest state-ofthe-art way to numerically cope with these types of problems.

\section{Acknowledgement}

This paper forms a part of the project L2-6775 Simulation of industrial solidification proceesses under influence of electromagnetic fieleds. This work was partially performed within the Creative Core program (AHA-MOMENT) contract no. 3330-13-500031, cosupported by RSMIZS and European Regional Development Fund Research.

\section{REFERENCES}

${ }^{1}$ C. S. Chen, A. Karageorghis, Y. S. Smyrlis, The Method of Fundamental Solutions - A Meshless Method, Dynamic Publishers, Atlanta 2008

${ }^{2}$ V. D. Kupradze, Ž. Vyčisl. Mat. i Mat. Fiz., 4 (1964), 1118-1121

${ }^{3}$ V. D. Kupradze, M. A. Aleksidze, Methods Math. Phys., 4 (1964), 82-126, doi:10.1016/0041-5553(64)90006-0

${ }^{4}$ A. Poullikkas, A. Karageorghis, G. Georgiou, Computers \& Structures, 80 (2002), 365-370, doi:10.1016/S0045-7949(01)00174-2

${ }^{5}$ Y. S. Smyrlis, Mathematics of Comptation, 78 (2009), 1399-1434, doi:10.1090/S0025-5718-09-02191-7

${ }^{6}$ D. Redekop, R. S. W. Cheung, Comput Struct, 26 (1987), 703-707, doi:10.1016/0045-7949(87)90017-4

${ }^{7}$ G. S. A. Fam, Y. F. Rashed, Engineering Analysis with Boundary Elements, 33 (2009), 330-341, doi:10.1016/j.enganabound.2008.07. 002

${ }^{8}$ Y. J. Liu, Engineering Analysis with Boundary Elements, 34 (2010), 914-919, doi:10.1016/j.enganabound.2010.04.008

${ }^{9}$ B. Šarler, Engineering Analysis with Boundary Elements, 33 (2009), 1374-1382, doi:10.1016/j.enganabound.2009.06.008

${ }^{10}$ D. L. Young, K. H. Chen, J. T. Chen, J. H. Kao, CMES: Computer Modeling in Engineering \& Sciences, 19 (2007), 197-222, doi:10.3970/ cmes.2007.019.197

${ }^{11}$ D. L. Young, K. H. Chen, C. W. Lee, Journal of Computational Physics, 209 (2005), 290-321, doi:10.1016/j.jcp.2005.03.007

${ }^{12}$ W. Chen, F. Z. Wang, Engineering Analysis with Boundary Elements, 34 (2010), 530-532, doi:10.1016/j.enganabound.2009.12.002

${ }^{13}$ Q. G. Liu, B. Šarler, CMES: Computer Modeling in Engineering and Sciences, 91 (2013), 235-266, doi:10.3970/cmes.2013.091.235

${ }^{14}$ Q. G. Liu, B. Šarler, Mater. Tehnol., 47 (2013) 6, 789-793

${ }^{15}$ Q. G. Liu, B. Šarler, Engineering Analysis with Boundary Elements, 45 (2014), 68-78, doi:10.1016/j.enganabound.2014.01.020

${ }^{16}$ A. F. Bower, Applied Mechanics of Solids, CRC Press, USA Florida 2009

${ }^{17}$ T. C. T. Ting, Anisotropic Elasticity, Oxford Science Publications, Oxford 1996

${ }^{18}$ M. H. Aliabadi, The Boundary Element, Applications in Solids and Structures, 2ed, John Wiley \& Sons, Chichester 2006 